\title{
In Vitro Generation of Cartilage-Carrier-Constructs on Hydroxylapatite Ceramics with Different Surface Structures
}

\author{
Katharina Wiegandt ${ }^{1}$, Christiane Goepfert ${ }^{1}$, Teresa Richter ${ }^{1}$, Daniel Fritsch ${ }^{2}$, Rolf Janßen ${ }^{2}$ and Ralf \\ Pörtner*,1
}

\author{
Hamburg University of Technology, ${ }^{1}$ Institute of Bioprocess and Biosystems Engineering; ${ }^{2}$ Institute for Advanced \\ Ceramics, Germany
}

\begin{abstract}
Tissue engineering approaches for healing cartilage defects are partly limited by the inability to fix cartilage to bone during implantation. To overcome this problem, cartilage can be - already in vitro - generated on a ceramic carrier which serves as bone substitute. In this study, the influence of a hydroxylapatite carrier and its surface structure on the quality of tissue engineered cartilage was investigated. Application of the carrier reduced significantly biomechanical and biochemical properties of the generated tissue. In addition, slight changes in the quality of the formed matrix, in the adhesive strength between cartilage and biomaterial and in attachment and proliferation of a chondrocyte monolayer could be observed for commercial grade carriers, with respect to modified topographies obtained by smooth grinding/polishing. These first results demonstrated an influence of the carrier and its surface structure, but further research is needed for explaining the described effects and for optimization of cartilage-carrier-constructs.
\end{abstract}

Keywords: Cartilage, osteochondral implants, hydroxylapatite, surface structure.

\section{INTRODUCTION}

Generally, injuries of articular cartilage do not heal spontaneously and lead to joint pain and restricted functions [13]. Established treatments like lavage or shaving and debridment often only improve clinical symptoms for a certain time [1]. New tissue engineering methods aim to generate autologous cartilage tissue in vitro for restoration of the defect. Until now, these strategies lead to promising but not sufficient results [2].

These approaches are partly limited by a deficient fixation of engineered cartilage to bone after implantation $[1,4]$. Thus, our research is intended to generate osteochondral implants, which consist of a layer of cultivated cartilage grown on a ceramic carrier as bone equivalent in vitro. A mosaic-like implantation $[3,5]$ of these cartilage-carrierconstructs into cartilage-bone defects may provide a reconstructed surface area inside the knee joint.

The formation of an adequate connection between engineered cartilage and biomaterial is not established in vitro until now, mainly, because the cartilage-carrier interface has to withstand high shear stress when implanted in the joint [6]. It is known that several properties of the biomaterial have an impact on anchorage and tissue formation. These properties include chemical and physical characteristics such as surface composition, particle size and surface structure. Therefore, further research is needed to understand chondrocyte-substrate interactions [7-10]. In this work, the influence of varying surface structures of a ceramic carrier (Sponceram $\mathrm{HA}^{\circledR}$, Zellwerk, Germany) on the formation of cartilagecarrier-constructs in vitro was investigated.

*Address correspondence to this author at the Hamburg University of Technology, Institute of Bioprocess and Biosystems Engineering, Germany;

E-mail: poertner@tu-harburg.de
The ceramic carrier used is composed of hydroxylapatite (HA), derived from porcine bone. HA offers biocompatible, bioactive, osteoconductive and in some cases even osteoinductive properties $[11,12]$. Therefore, calcium phosphate with its natural occurrence in the human body is applied as bone substitute or as coating of hip prostheses as it is integrated within bone [13-15].

Several in vivo studies describe a more effective bone fixation of implants with rough than with smooth surfaces, which already indicates an influence of surface structure on tissue-biomaterial interaction $[7,10]$. In cell culture experiments, it was found that several cell types react to modified substrate surface topography, e.g. with an increase in adhesion, acceleration of cell movement, orientation, morphometric changes in the cells, cytoskeletal changes, changes in contact inhibition of movement, activation of phagocytosis or changes in gene expression $[8,9]$. One reason for these effects may be the selective adsorption and arrangement of certain proteins required for cell attachment [15]. In addition, it is hypothesized that other elements which are influenced by surface topography such as surface energy or wetting properties play a role in cell behaviour $[15,16]$. All these factors affect cell adhesion, morphology and bonding forces to the cell. Information reaching cells by the cytoskeletal reorganisation may activate signal transduction pathways which stimulate for instance proliferation or differentiation [17-19]. Even though previous studies have investigated cell reaction on modified substrate topography, little is known about how chondrocytes respond to changes in surface structure, especially when growing on hydroxylapatite $[8,15]$. It could be observed that effects vary between different cells types and materials used [7,9].

During cartilage tissue engineering, some given factors have to be considered. The initial cell number for the genera- 
tion of autologous implants is limited by the small size of a biopsy. Hence, chondrocytes have to be expanded until the required cell number is reached. But, re-differentiation became necessary after expansion, as proliferation of chondrocytes is accompanied by de-differentiation of cells. Dedifferentiated chondrocytes stop production of cartilagespecific extracellular matrix components, especially collagen type II and glycosaminoglycans, and acquire fibroblast-like morphology [20, 21].

Thus, osteochondral implants were generated according to the following cultivation principle $[22,23]$ : (a) explanted chondrocytes are expanded in monolayer culture until passage 3; (b) afterwards the cells are seeded onto a solid ceramic carrier (cell coating) and cultivated for two weeks; (c) simultaneously to step b expanded chondrocytes are suspended in alginate gel for two weeks to induce redifferentiation; (d) after two weeks the re-differentiated chondrocytes are eluted out of the alginate gel and sedimented on the cell coated carrier. These cartilage-carrierconstructs are then cultivated for cartilage formation for three weeks (high-density cell culture). The concept was successfully applied in mini-pigs [24].

\section{MATERIALS AND METHODS}

\section{Carrier Material}

For the generation of constructs a solid carrier (Sponceram $\mathrm{HA}^{\circledR}$, Zellwerk, Germany) with a diameter of $4.55 \mathrm{~mm}$ and a height of $2 \mathrm{~mm}$ was used. The carrier consisted of hydroxylapatite, derived by partially sintering ground porcine bone.

In this work, the surface structure of carriers was modified to determine the influence of the topography on cartilage formation in vitro. In a previous study, surface structuring of dense calcium phosphates was done by grinding and ultrasonic milling using abrasive B4C particles [25]. Considering the surface defect formation observed thereby on some of the dense and therefore hard samples, in the present study a much less abrasive procedure was used in order to reduce defect formation on Sponceram HA carriers; e.g. plain paper (smooth celluloses) and foils used for inkjet printing (rough polymer) were used as tools for careful manual grinding. The results confirm that already these rather smooth tools are effective for surface topography tailoring of Sponceram HA carriers.

The surface topography of each carrier was characterized with the aid of a Charge-coupled Device (CCD) Camera (see below). Before cultivation, carriers were placed in phosphate-buffered saline (PBS, Roth, Germany) overnight which was followed by an autoclaving step.

\section{Characterization of Surface Structure}

For specification of the surface structure of carriers a microscope (InfiniteFocus, Alicona, Germany) with a Charge-coupled Device Camera was used which generates a xyz data set of the topography. This can be used to create a 3D image by respective post processing. Furthermore, the Alicona system can be used to generate data concerning roughness and/or wear which, however, are only to a certain but limited degree comparable with the well known data obtained by tactile measurements. Therefore, in this study only 3D images are used for evaluating the variation in surface topography as shown in Fig. (2).

In general, this allows a high resolution characterization (approx. at the best $10 \mathrm{~nm}$ in $\mathrm{z}$ direction and $1-2 \mu \mathrm{m}$ in $\mathrm{x}-\mathrm{y}$ direction) of rough and non-plain surfaces in non contact mode.

\section{Generation of Cartilage-Carrier-Constructs}

Chondrocytes were isolated from a knee joint (femur) of an approximately 5 month old domestic pig by using hyaluronidase type III solution (Sigma-Aldrich, Germany), trypsin (Roth) and collagenase type Ia solution (SigmaAldrich).

Cartilage-carrier-constructs were generated according to the concept described above [22, 23]. Starting with an initial cell number of $2 \times 10^{5}$ cells for the generation of six constructs, chondrocytes were expanded in T-flasks (Roth) until passage 3 (step a). Proliferation of the cells was performed in DMEM (Dulbecco`s Modified Eagle Medium, PAA, Germany) supplemented with $10 \%$ (v/v) fetal calf serum (FCS, PAA), penicillin/streptomycin (100 $\mathrm{U} \mathrm{mL}^{-1}$ penicillin and $100 \mu \mathrm{g} \mathrm{mL}^{-1}$ streptomycin, PAA), $25 \mathrm{mM}$ HEPES (4-(2hydroxyethyl)-1-piperazineethanesulfonic acid, Roth) and $10 \mathrm{ng} \mathrm{mL}^{-1}$ FGF-b (human recombinant Fibroblast Growth Factor basic, CellConcepts, Germany) [26].

Chondrocytes were trypsinated from the T-flasks and $2 \times 10^{5}$ chondrocytes were sedimented onto each calcium phosphate carrier (see above) to form a cell layer (step $b$ ). To initiate cell proliferation within two weeks of cultivation, the above mentioned medium was used. Simultaneously, chondrocytes from the same preculture were immobilized in alginate beads $\left(1 \times 10^{6}\right.$ cells per $\mathrm{mL}$ alginate) during two weeks for re-differentiation and production of cartilage matrix (step c).

After recovering cells from the gel, cartilage-constructs were prepared. Therefore, $1.8 \times 10^{6}$ re-differentiated cells were centrifuged onto each cell coated carrier, located in a special device [22]. For the preparation of cartilageconstructs without using any carrier, $1.8 \times 10^{6}$ cells harvested from alginate culture were centrifuged in tubes $(50 \mathrm{~mL}$ falcon tubes, Roth). For two days, constructs remained in their devices or tubes to permit aggregation of cells and extracellular matrix. Afterwards, cartilage-constructs (same procedure for both methods) were transferred to 12-well-plates (Roth) and cultivated for three weeks altogether in a highdensity cell culture. Eight constructs of each condition were prepared.

During cultivation of alginate beads and cartilage-carrierconstructs, DMEM (PAA) supplemented with $10 \%(\mathrm{v} / \mathrm{v})$ porcine serum (PS, Gibco, Germany), penicillin/streptomycin $\left(100 \mathrm{U} \mathrm{mL}^{-1}\right.$ penicillin and $100 \mu \mathrm{g} \mathrm{mL}$ streptomycin, PAA), 25 mM HEPES (4-(2-hydroxyethyl)-1piperazineethanesulfonic acid, Roth), $0.28 \mathrm{mM}$ L-ascorbic acid 2-phosphate and $1 \mathrm{mM}$ cysteine (Sigma-Aldrich) was used to stimulate matrix production. Furthermore, during redifferentiation in alginate gel hIGF-I $\left(100 \mathrm{ng} \mathrm{mL}^{-1}\right.$, human recombinant Insulin like Growth factor 1, CellConcepts, Germany) and hTGF- $\beta 1$ (10 $\mathrm{ng} \mathrm{mL}^{-1}$, human recombinant Transforming Growth Factor beta1, CellConcepts) were added to the medium [27]. 
Medium was exchanged three times a week. All cultivations were performed at $37{ }^{\circ} \mathrm{C}$ under an atmosphere of $5 \%$ (v/v) $\mathrm{O}_{2}$ and $5 \%(\mathrm{v} / \mathrm{v}) \mathrm{CO}_{2}$.

\section{Biochemical Analysis}

To quantify biochemical properties of cartilage constructs, DNA and glycosaminoglycan (GAG) content was determined according to Buschmann et al. [28]. The generated tissue was digested enzymatically with a papain solution (Roche, Germany) overnight. The GAG content was then measured photometrically by staining with 1,9dimethylmethylene blue chloride (Serva, Germany) with chondroitin sulfate (Sigma-Aldrich) as the standard. After that, DNA content was determined using the fluorescence marker H33258 (Hoechst, Germany) with calf thymus DNA as the standard [for details see 22, 23].

\section{Histological Analysis}

For histological analysis carriers were removed from the constructs after cultivation by the help of tweezers and the generated tissue was fixed in formaldehyde (4\% in PBS, Roth). After dehydrating and embedding in paraffin, $5 \mu \mathrm{m}$ thick histological sections were prepared with a microtome (Leica, Germany) on object slides (Histo-Bond ${ }^{\circledR}$, Marienfeldt, Germany). Paraffin was removed by the aid of xylene. Afterwards, histological sections were rehydrated in solutions with decreasing alcohol concentrations.

The formation of collagen type I and collagen type II was confirmed by immunochemical staining of histological sections. In the first step, histological sections were immunostained separately with primary antibodies (Acris Antibodies, Germany) against collagen type I (clone I-8H5) or collagen type II (clone II-4C11). As secondary antibody, a biotinylated antibody (Goat anti-mouse, [ $\operatorname{IgG}(\mathrm{H}+\mathrm{L})$-biotin], Southern Biotech, USA) was used. Afterwards, these sections were incubated with a streptavidin/alkaline phosphatase complex (Linaris, Germany) and the final color development was carried out with the New Fuchsin chromogen (SigmaAldrich) [29]. Nuclei were stained with haematoxilin (Roth).

Distribution of glycosaminoglycans in the cultivated tissue was determined by a Safranin O staining. Therefore, hydrated sections were submerged in Fast Green solution (0.04\% in $0.2 \%$ acetic acid, VWR, Germany), afterwards washed in $1 \%$ acetic acid and then stained with Safranin O (0.2\% in $1 \%$ acetic acid, Sigma-Aldrich).

\section{Biomechanical Parameters}

The biomechanical parameters wet weight (Mettler AE200), height and the Young's Modulus of the cartilageconstructs were determined. For measuring the height and the Young's Modulus, a high-precision material testing equipment (Zwicki 1120, Zwick, Germany) was used. The Young's Modulus was determined by stepwise stressrelaxation tests (five steps with $4 \%$ of the uncompressed cartilage thickness each) according to Korhonen et al. [30]. The criterion for relaxation was a relaxation rate of less than $0.002 \mathrm{~N} \mathrm{~min}^{-1}$. The Young's Modulus was calculated from resulting stress-strain curve.

Stability (interface between cartilage and carrier) was established qualitatively by pulling the cartilage carefully with a tweezers.

\section{Scanning Electron Microscopy}

Scanning electron microscopy (SEM, Leo 1530, Zeiss, Germany) was used to photograph the cell coated carrier after two weeks in culture (step b). At the end of cultivation carriers were kept in a glutaraldehyde solution (5\% in PBS, Sigma-Aldrich) to fix the cells. After a minimum of one day, they were dehydrated by stepwise exchanging water with ethanol $(20 \%, 40 \%, 60 \%, 80 \%, 100 \%$ ethanol in PBS) and stored in $100 \%$ ethanol. The next day, ethanol was exchanged with amyl acetate (Sigma-Aldrich) for two hours in an amyl acetate-ethanol mixture $(1: 1 \mathrm{v} / \mathrm{v})$. Afterwards, carriers were stored in $100 \%$ amyl acetate overnight. Before carrying out the SEM, the samples were critical-point dried (Balzers, Germany) and gold-sputter coated (Sputter Coated S150B, Edwards, United Kingdom's).

\section{Statistics}

Statistics software NCSS97 was applied to evaluate statistical significance of the data ( $\mathrm{p}<0.05$, ANOVA).

\section{RESULTS}

\section{Characterization and Modification of the Surface Topog- raphy of Calcium Phosphate Carrier (Sponceram HA ${ }^{\circledR}$ )}

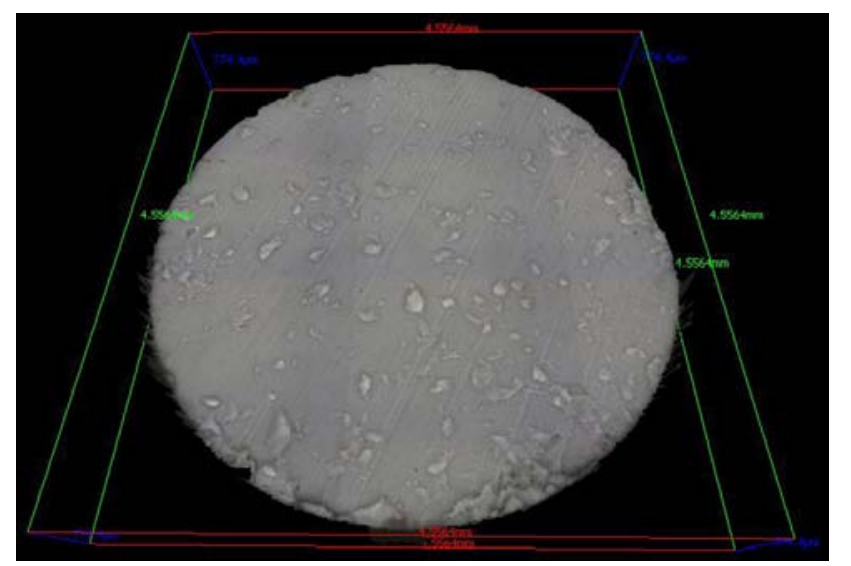

Fig. (1). Alicona image of a Sponceram HA carrier as used in this investigation. The defects are most probably due to cracking along some large agglomerates formed during calcinations of the porcine bone (each scale bar $=4,55 \mathrm{~mm}$ ).

Sponceram HA exhibits a disordered porous structure of coarse grains (compare Fig. 3 (1)). The mechanical durability of the material is low, even a conventional test of the surface roughness in contact mode resulted in low damage. Although the processing of this commercial material is not known in detail, it can be assumed that the calcination process of the porcine bone formed large agglomerates which contain most likely some organic residue. Therefore, sintering of the Sponceram HA powder compacts leads to weakly bonded grains with inter and intraporosity. The surface of the received Sponceram HA exhibits furthermore a wavy structure with large local defects - presumable, this surface reveals weak points of the manufacturing process.

In a preliminary study, conventional grinding/polishing or ultrasonic milling using abrasive $\mathrm{B} 4 \mathrm{C}$ particles, respectively, failed to create smooth and homogeneous surfaces [25]. Due to the local abrasive forces, fracturing along the large agglomerates occurred here once again resulting in 
crushing of the whole samples. Even soft materials like plain paper and polymer sheets as grinding tools did not reveal defect free surfaces. Still, these techniques could be used in order to modify the surface topography in the direction of smooth (using plain paper) or structured (using rough polymer sheets) compared to the rough and inhomogeneous untreated carrier as shown in Fig. (2).
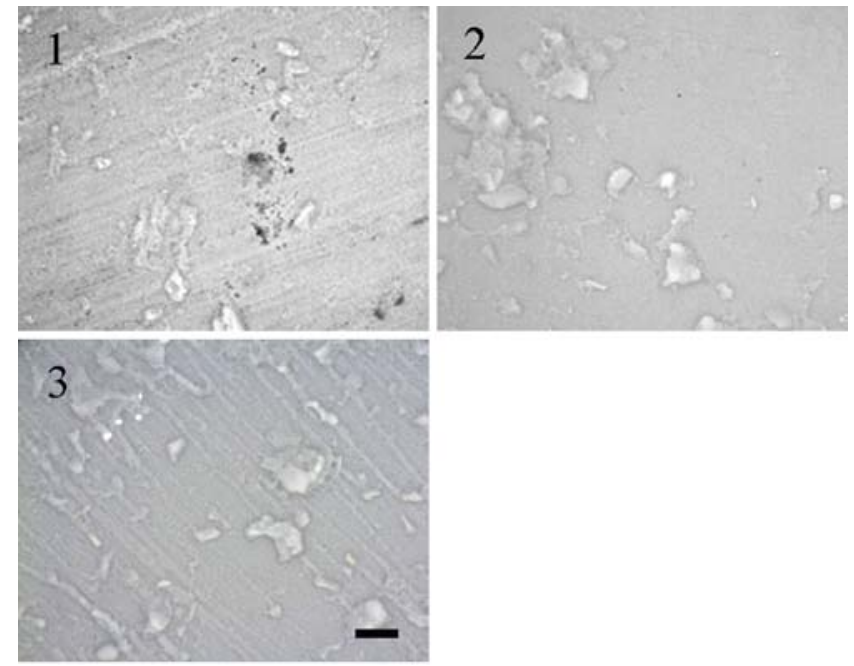

Fig. (2). Alicona images of (1) as received commercial grade Sponceram HA; (2) after surface tailoring using plain paper; (3) ink jet polymer sheet as grinding tools (scale bar $=200 \mu \mathrm{m}$ ).

\section{Influence of Modified Surface Topography on Cell At- tachment and Proliferation}

In previous studies, we observed a poor adhesive strength between carrier and chondrocytes recovered from alginate gel (step d). It was found that cells grown on the carrier as a first monolayer are necessary to improve the bonding before re-differentiated chondrocytes are added [31]. Hence, the formation of a cell layer on top of the modified carrier surfaces (step b) was investigated by scanning electron microscopy after two weeks of cultivation.

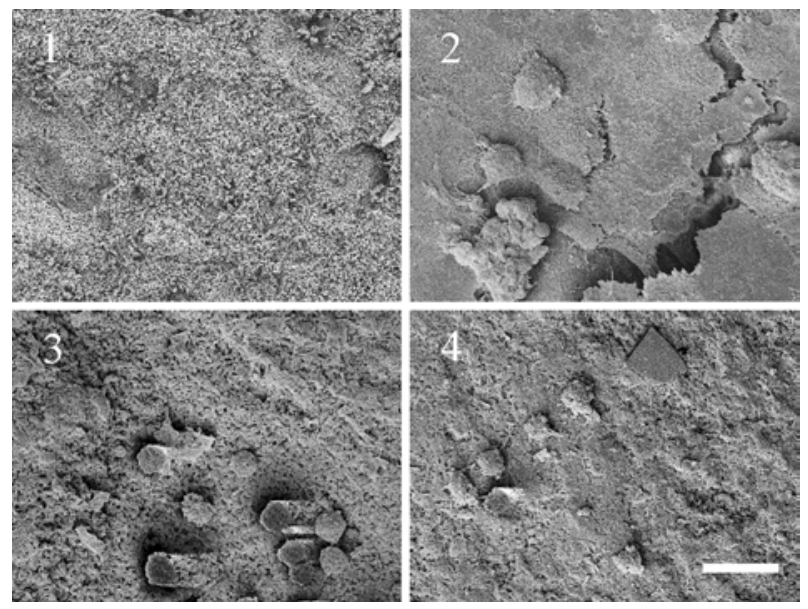

Fig. (3). SEM pictures of a cell layer grown on modified carrier surfaces (1) carrier without cells; (2) cell layer on HA carrier as received; (3) cell layer on HA carrier grinded using plain paper; (4) cell layer on HA carrier grinded using ink jet polymer sheet foil (scale bar $=20 \mu \mathrm{m})$.
In Fig. (3) differences in the development of the cell layer could be observed, dependent on the surface structure of the hydroxylapatite carrier. While the HA carrier as received shows a closed cell layer, only a low cell number is visible on the top of the carrier grinded with plain paper or ink jet polymer sheet foil.

\section{Influence of Modified Surface Topography on the Qual- ity of Cartilage-Carrier-Constructs}

After evaluation of the developed cell layer, cartilagecarrier-constructs have been prepared using carriers with different surface structures. In addition, tissue engineered cartilage was generated without using any carrier.

The largest constructs were found for the cultivation without using a carrier which is shown by significantly higher wet weights and heights (Fig. 4). These constructs exhibited also the significantly highest Young's Modulus of $0.052 \mathrm{MPa}$. Constructs using carriers grinded with plain paper or with ink jet foil showed higher biomechanical properties than those using untreated carriers. However, only the height of the cartilage-carrier-constructs grinded with paper yielded in a significant difference to the untreated carriers.

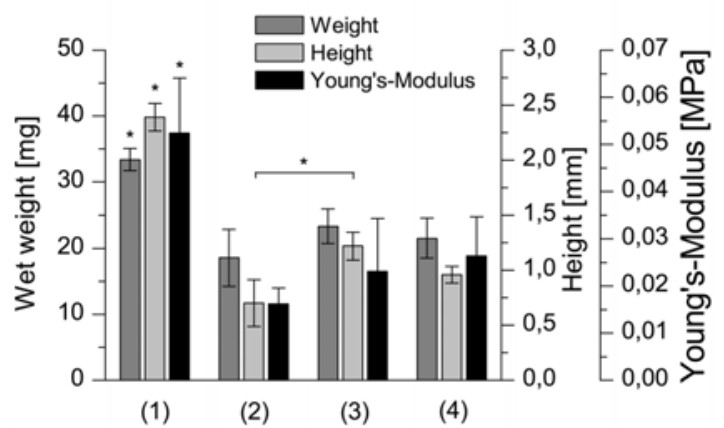

Fig. (4). Biomechanical parameters wet weight, height and Young's Modulus of cartilage-constructs cultured (1) without using a carrier; (2) with a HA carrier as received; (3) with a HA carrier grinded using plain paper; (4) with a HA carrier grinded using ink jet polymer sheet foil $(n=6, p<0.05)$.

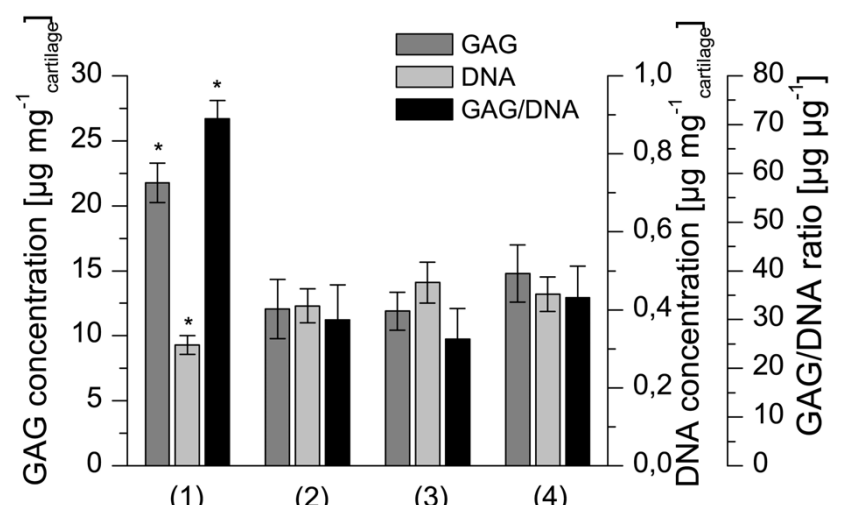

(1)

(2)

(3)

(4)

Fig. (5). Biochemical parameters glycosaminoglycan concentration, DNA concentration and GAG to DNA ratio of cartilage-constructs cultured (1) without using a carrier; (2) with a HA carrier as received; (3) with a HA carrier grinded using plain paper; (4) with a HA carrier grinded using ink jet polymer sheet foil $(n=6, p<0.05)$. 
The significantly highest glycosaminoglycan content and GAG to DNA ratio have been reached for cartilageconstructs using no carrier (Fig. 5). The DNA concentration is significantly lower compared to the cultivation with carriers. Differences in the biochemical parameters could be hardly observed when comparing cartilage-carrier-constructs with modified surface topographies among each other.

Even though the histological sections in Fig. (6) showed a tissue without any wholes in all cases, only constructs cultured without any carriers developed homogenous tissue in which chondrocytes were evenly distributed. Most notably, in constructs grown on the top of an untreated carrier glycosaminoglycans are unequally distributed.
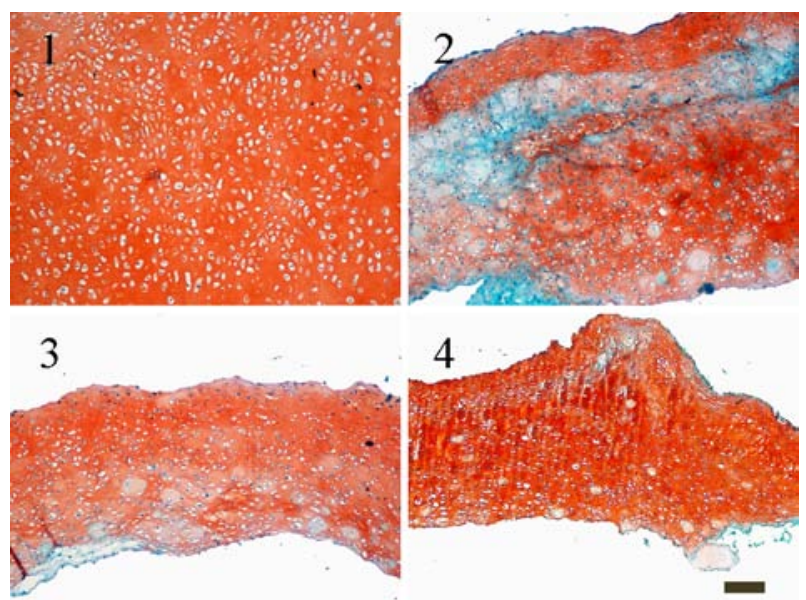

Fig. (6). Histological staining for glycosaminoglycans with Safranin $\mathrm{O}$ (1) constructs cultured without using a carrier; (2) constructs cultured with HA carrier as received; (3) constructs cultured with a HA carrier grinded using plain paper; (4) constructs cultured with a HA carrier grinded using ink jet polymer sheet foil (scale bar $=100 \mu \mathrm{m}$ ).

The immunohistological images (Fig. 7) show a more prominent staining for collagen type II than for collagen type I for all culture conditions. Again, the staining of the unsupported cartilage construct is uniform, while areas with more or less collagen type I and II appeared in constructs cultured with carriers.

In addition, the adhesive strength between carrier and tissue was estimated by applying subjective values. Cartilage was detached from the biomaterial with the help of tweezers and different adhesions were noted. The connection between tissue and biomaterial was weaker for constructs on top of carriers grinded with paper and ink jet foil than for untreated carriers.

\section{DISCUSSION}

One approach for the treatment of cartilage defects is the generation of autologous tissue in vitro, which can be implanted into the joint. As the fixation of engineered cartilage to bone $[1,4]$ frequently causes problems inside the body, tissue engineered cartilage can be cultured on top of a ceramic carrier which acts as bone equivalent. However, demands on the adhesive strength of the cartilage to substrate interaction are high in vitro. From several studies with different biomaterials and cell types, it is known that surface topography is one factor which influences cell adhesion and behavior [8, 9]. In this work, cartilage-carrier-constructs grown on different surface structures of hydroxylapatite ceramics based of porcine bone were prepared and analyzed.

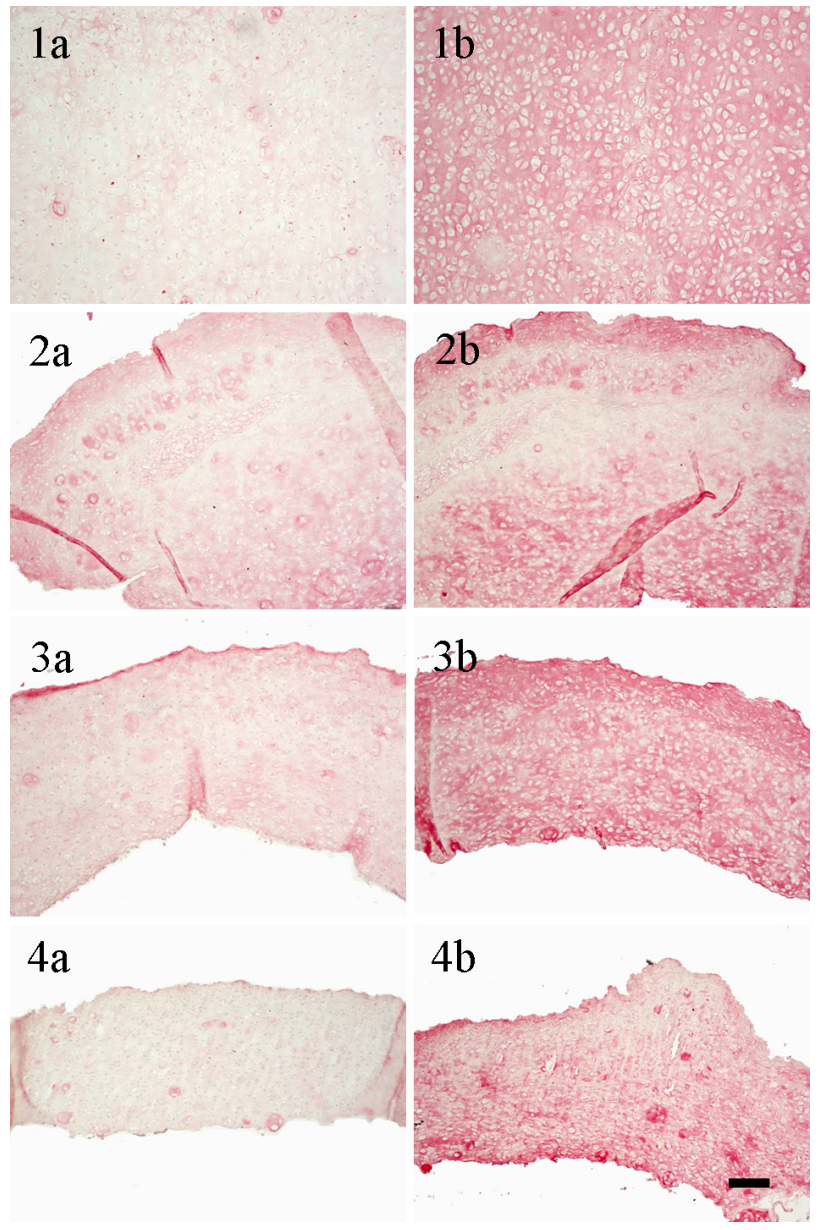

Fig. (7). Immunohistological staining: left column for collagen type I, right column for collagen type II $(\mathbf{1 a}) /(\mathbf{1 b})$ constructs cultured without using a carrier; $(\mathbf{2 a}) /(\mathbf{2 b})$ constructs cultured with a HA carrier as received; $(\mathbf{3 a}) /(\mathbf{3 b})$ constructs cultured with a HA carrier grinded using plain paper; $(\mathbf{4 a}) /(\mathbf{4 b})$ constructs cultured with a HA carrier grinded using ink jet polymer sheet; (scale bar $=100 \mu \mathrm{m})$.

Research being carried out to determine cell-surface interaction concerning physical parameters of the biomaterial deals with particle size, porosity and topography using different cell types [9, 32, 33]. In this work, the surfaces of hydroxylapatite carriers were modified by grinding either with plain paper resulting in smooth surfaces or with ink jet foil resulting in structured surfaces, while the surface of the commercial grade carrier is rough and inhomogeneous. In the first step, chondrocytes were sedimented onto the carriers for expansion. After two weeks, considerable differences in the formed cell layer were visible (Fig. 3). While the commercial grade carrier showed a closed cell layer, fewer cells are grown on the top of the carrier grinded with paper or with ink jet foil. It can be concluded that under the described conditions the used chondrocytes favor inhomogeneous hydroxylapatite structures. Data from literature concerning cell adhesion and proliferation on different surface structures are controversial. While Boyan et al. [10] found a decrease in cell number of growth and resting zone chondrocytes on rough compared to smooth titanium surfaces, Deligianni 
Table 1. Summarization of Biochemical and Biophysical Parameters of Generated Cartilage Constructs (+ Positive Results; Negative Results; +/- no Difference; ++ Significantly Highest Values)

\begin{tabular}{|c|c|c|c|c|}
\hline Surface Modification & w/o Carrier & Carrier as Received & Carrier Grinded with Paper & Carrier Grinded with Foil \\
\hline \hline Surface structure & & rough and inhomogeneous & smooth \\
\hline Proliferation (monolayer) & + & + & - & - \\
\hline Adhesive strength & ++ & - & + & + \\
\hline $\begin{array}{c}\text { Biomechanical } \\
\text { quality }\end{array}$ & ++ & $+/-$ & $+/-$ & + structured \\
\hline $\begin{array}{c}\text { Biochemical } \\
\text { quality }\end{array}$ & ++ & - & + & + \\
\hline Histology & & + & + \\
\hline
\end{tabular}

et al. [15] observed an increase of cell attachment and proliferation of bone marrow cells on rough hydroxylapatite surfaces. Besides, further studies monitored an orientation of cells longitudinal to grooves [15] and a change in chondrocytes movement on substrata dependent on the dimension of grooves [8]. Varying results may be attributed to differences in the degree of roughness, biomaterials and cell types used, species and age of donors, status of cell differentiation or differences in culture conditions like addition of serum, proteins or growth factors.

Additionally, cartilage-carrier-constructs were generated on top of carriers with three different surfaces during this study. A strong connection between cartilage to biomaterial interface is an important factor as it has to resist high shear stresses after implantation in the joint [6]. Adhesion between tissue and biomaterial was weaker for constructs on top of carriers grinded with plain paper and ink jet foil than for untreated carriers, which was estimated by detachment of the cartilage from the substrata by means of tweezers. This corresponds to the finding after expanding cells on top of the modified carriers (Table 1), where most cells could be found on the untreated inhomogeneous carrier.

Slight differences could be observed between the biomechanical and biochemical quality of constructs. The wet weight, height and Young's Modulus of cartilage cultured on the untreated carrier reached lower values than the other two conditions, but only the difference in height is significant. Also, histological staining for glycosaminoglycans (Fig. 6) and collagen type I and II (Fig. 7) showed a more irregular distribution for constructs grown on untreated hydroxylapatite ceramics.

Furthermore, it was demonstrated that tissue engineered cartilage cultured without any carrier yielded the significantly highest biochemical and biomechanical parameters (Figs. 4 and 5), compared to cartilage-carrier-constructs. The Young's Modulus achieved $(0.052 \mathrm{MPa})$ reached $13 \%$, the GAG to DNA ratio $\left(71.2 \mu \mathrm{g} \mu \mathrm{g}^{-1}\right)$ actually $43 \%$ of native values. Histological sections stained either with Safranin O or against collagen type I and type II showed homogenous tissue (Figs. 6 and 7). Glycosaminoglycans as part of extracellular cartilage matrix were evenly distributed and the staining for the cartilage-specific collagen type II was more intensive than for collagen type I. The latter is generally not present in articular cartilage [20]. The results suggest that the carrier itself has a strong influence on the formation of tissue engineered cartilage. The Young's Modulus and the GAG to DNA ratio of constructs cultured with a carrier were about $60 \%$ lower on average than the unsupported tissue. The images in Figs. (6 and 7) show that these values arise not only by differences of the tissue formed in the interface between biomaterial and cartilage, but by the whole engineered cartilage. Otherwise less glycosaminoglycans and collagen type II should be visible in the lower areas of tissue in Fig. (6). Thus, it is most likely that cells in the interface transfer the interaction of the carrier to farther chondrocytes.

Supplementary, tissue generation on top of a carrier is affected by a bad nutrient supply from the bottom. Diffusion of nutrients and gases are hindered by the carrier itself and the holding device for the carrier.

In conclusion, inhomogeneous and rough surfaces of hydroxylapatites support the proliferation and adhesion of cells and tissue, but lead to inferior quality of the engineered matrix (Table 1). Possibly, the negative influence of the carrier described above was increased by the stronger adhesive force and connection to the cultivated cartilage using the untreated carrier compared to the modified smooth and structured surface topographies.

\section{CONCLUSION}

Hydroxylapatite ceramics themselves have a negative effect on the quality of cartilage-constructs generated in vitro compared to unsupported tissue. It has to be noted that these impacts are not limited to the cartilage-biomaterial interface.

It could be demonstrated that moderate surface structure modifications of commercial carriers causes slight changes in biomechanical quality of cartilage constructs, in the distribution of proteoglycans and collagens, in the adhesive strength between cartilage and biomaterial and in attachment and proliferation of a chondrocyte monolayer. This study delivered first interesting results of the influence of a hydroxylapatite carrier and its surface topography on the formation of cartilage tissue in vitro. However, from these findings the described effects cannot be explained and further research is needed to improve the connection between engineered cartilage and ceramic carrier.

\section{ACKNOWLEDGEMENTS}

We would like to thank Kerstin Michael and Ditte Siemesgelüss for their excellent technical support, Helge Paetzold for his help during Young's Modulus measure- 
ments and Oscar for proofreading. The project was kindly supported by DFG (PO 413/7-1).

\section{REFERENCES}

[1] J. Petersen, A. Ruecker, D. von Stechow, P. Adamietz, R. Pörtner, J. Rüger, and N. Mennen, "Present and future therapies of articular cartilage defects", Eur. J. Trauma, vol. 29, pp. 1-10, 2003.

[2] E. Hunziker, "Articular cartilage repair: basic science and clinical progress. A review of the current status and prospects", Osteoarthritis Cartilage, vol. 10, pp. 432-463, 2001.

[3] L. Hangod, and P. Füles, "Autologous osteochondral mosaicplasty for the treatment of full-thickness defects of weight-bearing joints", J. Bone Joint Surg. Am., vol. 85, pp. 25-32, 2003.

[4] S. Waldman, M. Grynpas, R. Pilliasa, and R. Kandel, "Characterization of cartilaginous tissue formed on calcium polyphosphate substrates in vitro", J. Biomed. Mater. Res., vol. 62, pp. 323-330, 2002.

[5] P. Behrens, U. Bosch, J Bruns, C. Erggelet, S. Esenwein, C. Gaissmaier, T. Krackhardt, J. Lohnert, S. Marlovits, N. Meenen, J. Mollenhauer, S. Nehrer, F. Niethard, U. Noth, C. Perka, W. Richter, D. Schafer, U. Schneider, M. Steinwachs, and K. Weise, "Recommendations for indication and application of ACT of the joint advisory board of the German Society for Traumatology (DGU) and Orthopaedic Surgery (DGOOC)", Z. Orthop., vol. 142, pp. 529-539, 2004.

[6] K. Allan, R. Pilliar, J. Wang, M. Grynpas, and R. Kandel, "Formation of biphasic constructs containing cartilage with a calcified zone interface", Tissue Eng., vol. 13, pp. 167-177, 2007.

[7] Z. Schwartz, J. Martin, D. Dean, J. Simpson, D. Cochran, and B. Boyan. "Effect of titanium surface roughness on chondrocyte proliferation, matrix production, and differentiation depends on the state of cell maturation", J. Biomed. Mater. Res., vol. 30, pp. 145$155,1997$.

[8] D. Hamilton, M. Riehle, R. Rappuolo, W. Monaghan, R. Barbucci, and A. Curtis. "The response of primary articular chondrocytes to micrometric surface topography and sulphated hyaluronic acidbased matrices", Cell Biol. Int., vol. 29, pp. 605-615, 2005.

[9] A. Curtis, and C. Wilkinson, "Reactions of cells to topography", $J$. Biomater., vol. 9, pp. 1313-1329, 1998.

[10] B. Boyan, J. Lincks, C. Lohmann, V. Sylvia, D. Cochran, C. Blanchard, D. Dean, and Z. Schwartz, "Effect of surface roughness and composition on osteochondral chondrocytes is dependent on cell maturation state", J. Orthop. Res., vol. 17, pp. 446-457, 1999.

[11] C. Rodrigues, P. Serricella, A. Linhares, R. Guerdes, R. Borojevic, M. Rossi, M. Duarte, and M. Farina, "Characterization of a bovine collagen-hydroxylapatite composite scaffold for bone tissue engineering", Biomaterials, vol.24, pp. 4987-4997, 2003.

[12] C. Teixeira, Y. Nemelivsky, C. Karkia, and R. Legeros, "Biphasic calcium phosphate: a scaffold for growth plate chondrocyte maturation", Tissue Eng., vol. 8, pp. 2283-2289, 2006.

[13] M. Epple. Biomaterialien und Biomineralisation. Teubner Studienbücher Chemie, 2003.

[14] Z. Schwartz, G. Braun, D. Kohavi, B. Brooks, D. Amir, J. Sela, and B. Boyan, "Effects of hydroxalapatite implants on primary mineralization during rat tibial healing: biochemical and morphometric analyses", J. Biomed. Mater. Res., vol. 27, pp. 1029-1038, 1993.

[15] D. Deligianni, N. Katsala, P. Koutsoukos, and Y. Missirlis, "Effect of surface roughness of hydroxylapatite on human bone marrow cell adhesion, proliferation, differentiation and detachment strength", Biomaterials, vol. 22, pp. 87-96, 2001.

[16] B. Boyan, T. Hummert, D. Dean, and Z. Schwartz, "Role of material surfaces in regulating bone and cartilage cell response", Biomaterials, vol. 17, pp. 137-146, 1996.

[17] C. Selhuber, "Biological adhesion of nanopatterned substrates studied with force spectroscopy and microinterferometry", $\mathrm{PhD}$ thesis, University of Heidelberg, Germany, 2006.
[18] E. dos Santos, M. Farina, and G. Soares, "Surface energy of hydroxylapatite and $\beta$-tricalcium phoasphate ceramics driving serum protein adsorption and osteoblast adhesion", J. Mater. Sci. Mater. Med., vol. 19, pp. 2307-2316. 2008.

[19] R. Lebaron, and K. Athanasiou, "Extracellular matrix adhesion peptides: functional applications in orthopedic materials", Tissue Eng., vol. 6, pp 85-103, 2000.

[20] M. Pei, J. Seidel, G. Vunjak-Novakovic, and L. Freed, "Growth factors for sequential cellular de- and re-differentiation in tissue engineering", Biochem. Biophys. Res. Commun., vol. 294, pp.149$154,2002$.

[21] M. Jakob, O. Demarteau, D. Schäfer, B. Hintermann, W. Dick, M. Heberer, and I. Martin, "Specific growth factors during the expansion and redifferentiation of adult human articular chondrocytes enhances chondrogenesis and cartilaginous tissue formation", $J$. Cell Biochem., vol. 81, pp. 368-377, 2001

[22] S. Nagel-Heyer, C. Goepfert, M. Morlock, and R. Pörtner, "Relationship between physical, biochemical and biomechanical properties of tissue-engineered cartilage-carrier-constructs", Biotechnol. Lett., vol. 27, pp. 187-192, 2005.

[23] S. Nagel-Heyer, C. Goepfert, F. Feyerabend, J. Petersen, P. Adamietz, N. Meenen, and R. Pörtner, "Bioreactor cultivation of threedimensional cartilage-carrier-constructs", Bioprocess Biosyst. Eng., vol. 27, pp. 271-280, 2005.

[24] J. Petersen, P. Üblacker, C. Goepfert, C. Adamietz, K. Baumbach, A. Stork, J. Ruegen, R. Pörtner, M. Amling, and N. Meenen, "Long term results after implantation of tissue engineered cartilage for the treatment after osteochondral lesions in a mini pig model", J. Mater. Sci. Mater. Med., vol. 19, pp. 2029-38, 2008.

[25] R. Janssen, S. Nagel-Heyer, C. Goepfert, R. Pörtner, D. Toykan, Krummhauer, M. Morlock, P. Adamietz, N. Meenen, W. Kriven, D. Kim, A. Tampieri, and G. Celotti, "Calcium phosphate ceramics as substrate for cartilage cultivation“, Ceram. Eng. Sci. Proc., vol. 25 , pp. 523-528, 2004

[26] I. Martin, G. Vunjak-Novakovic, J. Yang, R. Langer, and L. Freed, "Mammalian chondrocytes expanded in the presence of fibroblast growth factor 2 maintain the ability to differentiate and regenerate three-dimensional cartilaginous tissue", Exp. Cell Res., vol. 253 pp. 681-688, 1999.

[27] K. Wiegandt, C. Goepfert, and R. Pörtner, "Improving in vitro generated cartilage-carrier-constructs by optimizing growth factor combination”, Open Biomed. Eng. J., vol. 1, pp. 85-90, 2007.

[28] M. Buschmann, Y. Gluzband, A. Grodzinski, J. Kimura, and E. Hunziger, "Chondrocytes in agarose culture synthesis a mechanically functional extracellular matrix", J. Orthop. Res., vol. 10, pp. 745-758, 1992

[29] C. Goepfert, V. Lutz, S. Lünse, K. Wiegandt, M. Kammal, K. Püschel, and R. Pörtner, "Redifferentiation capacity of human articular chondrocytes (HAC) expanded on microcarriers", in Abstracts of $2^{\text {nd }}$ International Conference "Strategies in tissue Engineering", Cytotherapy, vol. 8, p. 29, 2006.

[30] R. Korhonen, M. Laasanen, J. Toyras, J. Rieppo, J. Hirvonen, H. Helminen, and J. Jurvelin, "Comparison of the equilibrium response of articular cartilage in unconfined compression, confined compression and indentation", J. Biomech., vol. 35, pp. 903-909, 2002.

[31] C. Goepfert, R. Böer, S. Nagel-Heyer, D. Toykan, P. Adamietz, R. Janssen, and R. Pörtner, "Formation of tissue-engineered cartilage on different types of calcium phosphate ceramics", in Cytotherapy, 2004, pp. 270-271.

[32] O. Gauthier, J. Bouler, E. Aguado, P. Pilet, and G. Daculsi, "Macroporous biphasic calcium phosphate ceramics: influence of macropore diameter and macroporosity percentage on bone ingrowth", Biomaterials, vol. 19, pp. 133-139, 1998.

[33] C. Spiteri, R. Pilliar, and R. Kandel, "Substrate porosity enhances chondrocyte attachment, spreading, and cartilage tissue formation in vitro", J. Biomed. Mater. Res., vol. 74, pp. 676-683, 2006.

(C) Wiegandt et al.; Licensee Bentham Open.

This is an open access article licensed under the terms of the Creative Commons Attribution Non-Commercial License (http://creativecommons.org/licenses/by-nc/3.0/) which permits unrestricted, non-commercial use, distribution and reproduction in any medium, provided the work is properly cited. 